\title{
Challenges in Upgrading Emergency Power in Florida Nursing Homes following Hurricane Irma
}

\author{
Nicole S. Hutton ${ }^{\mathrm{a}}$ And Michael J. Allen ${ }^{\mathrm{a}}$ \\ ${ }^{a}$ Department of Political Science and Geography, Old Dominion University, Norfolk, Virginia
}

(Manuscript received 4 June 2019, in final form 31 August 2020)

\begin{abstract}
Maintaining and restoring electricity after a disaster helps to preserve the health and well-being of the elderly who are at increased risk of heat stress and may be dependent upon life-sustaining medical equipment. Mitigation policies altered in reaction to increased public interest without thorough consideration of industry-specific resources may contribute to delays in implementation and unrealized potential for emergency power coverage within individual facilities. The objectives of this research are twofold: (i) to examine the relationship between preexisting conditions of life-safety systems at facilities and date of implementation of emergency power regulation improvements and (ii) to assess the role of interagency connections - such as emergency management, fire safety, health care administration, and electricity providers-in facilitating compliance with safety regulations. A case study regarding the capacity to implement new emergency power regulations was conducted in Florida with 12 nursing homes affected by Hurricane Irma. The proposals to maintain temperatures and life-sustaining equipment under the updated regulations were not consistent among nursing homes within each county or between counties. Facilities with no preexisting life-safety violations were among the first to comply with new emergency power regulations. Those with prior violations often utilized procedural updates and external resources to comply. Nursing facilities that required additional support for remediation prior to the storm had plans approved earlier or without a second review as compared with those relying on internal resources. These results establish a baseline for the conditions associated with timely compliance including the importance of collective agency to mitigate risk.
\end{abstract}

KEYWORDS: Emergency preparedness; Emergency response; Risk assessment

\section{Introduction}

Hurricane Irma made landfall in Collier County, Florida, as a category-3 storm on 10 September 2017 and passed through Polk County, Florida, on 11 September 2017 (Fig. 1) (NHC 2017). The storm was the most intense to make landfall in the United States since Hurricane Katrina (Issa et al. 2018). Although a majority of the 6.7 million power outages in the state of Florida were resolved within a week of Hurricane Irma (Florida Division of Emergency Management 2017b) some areas throughout the state were still without power 2 weeks later.

\section{a. Progression of the legislation}

In response to postdisaster fatalities in nursing homes, Florida Governor Rick Scott enacted an emergency action on 16 September 2017. The order required that emergency power plans of skilled nursing and assisted living facilities be updated to adopt changes to power supplies - such as ensuring adequate generator capacity, fuel storage, and fuel delivery arrangements - within 60 days (Florida Division of Emergency Management 2017a).

The governor's emergency action became permanent in March 2018 when he approved Rule 59 A-4.1265. It required nursing homes to provide $30 \mathrm{ft}^{2}\left(\sim 2.8 \mathrm{~m}^{2}\right)$ of space per resident, cooled to $81^{\circ} \mathrm{F}\left(\sim 27^{\circ} \mathrm{C}\right)$ or lower. A total of $96 \mathrm{~h}$ of fuel for backup power generation should be available between on-site and off-site resources. Future generator maintenance in compliance with the life-safety code, fire prevention code, flammable and combustible liquids code, and standard for liquefied natural gas was also mandatory. Further, Rule 59 A-4.1265

Corresponding author: Nicole S. Hutton,nhuttons@odu.edu extended the emergency power plan submission deadline to April 2018 and implementation to June 2018. Statewide demands for increased generator and fuel storage capacity as well as the increased number of inspections needed for upgraded emergency power supplies delayed the receipt of new generators. Consequently, the permanent legislation further extended compliance deadlines to 1 January 2019, and 523 facilities received extensions. During the 2018 hurricane season, when another major storm, Hurricane Michael, made landfall along the Florida Panhandle, only 184 of Florida's nursing homes met the state's new emergency power supply regulations (Sexton 2018). By 1 January 2019, the Florida Agency for Health Care Administration (2017) reported that 489 facilities had not complied.

\section{b. Heat, evacuation, and the elderly}

Extreme weather contributes to power failure. For example, tropical cyclones blow debris and disrupt power lines (Panteli and Mancarella 2015). Prolonged power outages contribute to a range of adverse health outcomes; heat-related fatalities increase during blackouts (Anderson and Bell 2012; Byrd and Matthewman 2014; Klinger et al. 2014; Pescaroli and Alexander 2016). Medical and social factors contribute to the elderly's increased vulnerability to fluctuating environmental conditions, such as heat (Gronlund et al. 2016; Åström et al. 2011; Hajat et al. 2010; Kovats and Hajat 2008). Studies have also shown that reduced access to cooled spaces increases their negative health outcomes as periods of elevated temperature reduce thermoregulatory capacity (Eisenman et al. 2016). Failed generators can increase heat-related morbidity or mortality because no equipment, including that for cooling, 


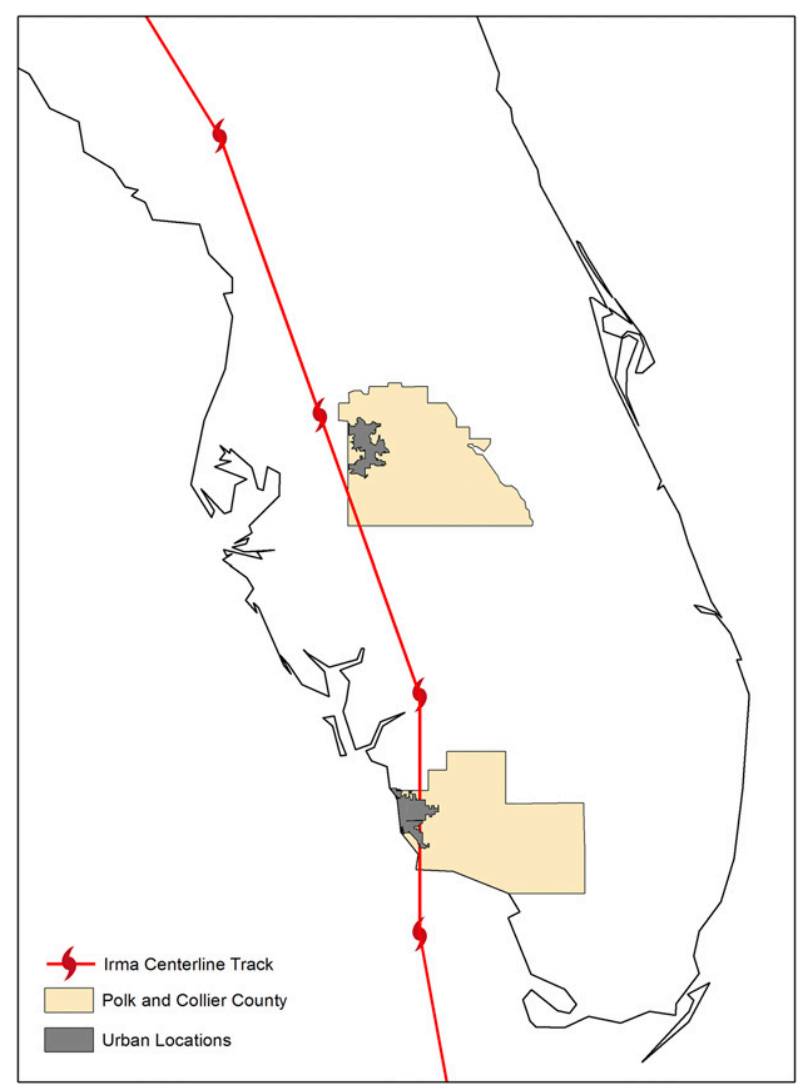

FIG. 1. Track of Hurricane Irma (adapted from NHC 2017).

receives backup power (Smith et al. 2009). The accessibility of resources to provide and sustain adequate emergency power is critical to preserving life in elder-care facilities.

Power outages may delay emergency responders, limit access to health care facilities, and increase demand for generators and fuel to the point where availability of these assets becomes scarce (Beatty et al. 2006; Hiete et al. 2011). Backup power is not always guaranteed due to generator malfunction (Kile et al. 2005). Infrastructural expansion offers a possible solution to reduce heat vulnerability (Sheridan and Allen 2018). The way to leverage cross-sectoral resources to prioritize and implement infrastructural improvements needs to be further explored (Palm 2009).

Nursing homes are under increased community scrutiny because of the vulnerable population they serve (Montz et al. 2017). Care facilities must evacuate early and at great expense, and therefore many opt to shelter in place (Hyer et al. 2006). Clearly defined emergency staffing requirements and management roles benefit facility decision-makers (Qureshi et al. 2005). The decision to evacuate or prepare to shelter in place is a complex one within the authority of facility management (Root et al. 2007). On the one hand, Hyer (2013) found residents that do evacuate have higher death rates and requirements for acute care. On the other hand, those sheltering in place are dependent upon the facility to withstand wind and flood damage, meet power, food, and water demands and access hospitals to address emergent or heightened resident health concerns (Hyer 2013). Hurricane Katrina was an example of how facility failure contributes to increased deaths with over 100 nursing-home-resident deaths among those that sheltered in place (Hyer 2013). A clear description of resident risk, available resources, and both internal and external communication should be included in evacuation decision-making and emergency plans for sheltering in place (Hyer et al. 2007; Hyer 2013).

A nursing home's internal resources are not expected to suffice during a disaster (Myers and Bearss 2018). Coordination with local and state partners facilitates shared best practices and planning strategies to increase each facility's capacity to simulate and manage natural-hazard-related emergencies. The Centers for Medicare and Medicaid Services (CMS) emergency preparedness rule (CMS 2016) addressed previous shortcomings in federal certification standards for state and local collaboration to prepare skilled nursing facilities for hazards (Brown et al. 2007). The CMS emergency preparedness rule also indicates a need for participation in emergency simulations with external responders, which Whytlaw (2018) shows is an indicator of success when a nursing-home facility encounters a hazard. Specifically, emergency management exercises promote consistent levels of coordination between nursing-home administrators, external contractors and government officials across a given state, which would otherwise vary based on individual perceptions of the importance of collaboration (Whytlaw 2018).

The CMS emergency preparedness rule is an example of coordination between health advocates and policy makers, which is a vital for improving disaster outcomes for the elderly (Aldrich and Benson 2008; Myers and Bearss 2018). Successful advocacy allowed for the endorsement of the National Fire Protection Association standards for generator maintenance instead of creating redundancies and allowed facilities to include only the hazards relevant to their area in their plans (Myers and Bearss 2018). Public-private sector coordination provides a balance between the needed reforms and the financial stress and increased burdens on staff and officials that they cause (Myers and Bearss 2018). In the case of Hurricane Irma, preparedness measures were not always aligned with the damage potential or track because of a lack of existing policy requirements and engineering capability (Senkbeil et al. 2020, 2019). Since hurricanes are a known hazard for the state of Florida, uniform regulation is desirable (Myers and Bearss 2018). Additional research is needed to identify how interagency connections influence policy implementation timelines.

\section{c. Postdisaster organizational resilience}

For elder-care facilities to continue to serve as many patients as possible, they must maintain public trust. In areas with hazard risk, it is imperative that facilities make the public aware of preparedness plans and mitigation technologies (Oleske 2001). Continuity of services and implementation of mitigation initiatives, such as increased emergency power supply regulation, is bolstered by both collaboration and redundancy (Weichselgartner and Kelman 2015). The initial driver of postdisaster organizational resilience for nonprofit health care and social services is incorporating emergent public demand (Hutton et al. 2016). Public perception expands after 
blackouts to include access to cooled spaces for the elderly (Abi Ghanem et al. 2016; Klinger et al. 2014). Specifically, Hurricane Irma increased societal interest in elder care because nursing-home residents died from heat-related causes in Hollywood, Florida (Chakalian et al. 2019; Pierce and West 2017).

The indicator of organizational resilience changes to alignment with government and other industry-specific partners as the emergency stages progress (Hutton 2019). For Florida nursing homes, this shift in focus from one stage to the next allowed for revision of the original emergency action to ensure appropriate levels of governance were consulted in policy formation and implementation. Collective action and collaborative oversight have the potential to sustain resilience gained from incorporating increased public demand through prioritization and resource sharing (Hutton 2018). For example, Helsloot and Beerens (2009) documented that local governments capacity can be temporarily redirected to support the elderly after a blackout (Helsloot and Beerens 2009). The existing federal, state, and local relationship between fire safety and emergency preparedness requirements provided structure but not necessarily the local capacity to scale up in time for rapid implementation in Florida. Accounting for this discrepancy, Rule 59 A-4.1265 extended the compliance timeline. Therefore, demonstrating progress toward implementation in conjunction with partners became sufficient to sustain perceived resilience. Additional investigation into who is overseeing and administering regulatory compliance is needed to determine the legitimacy and translation of perceived resilience to realized hazard mitigation.

A disconnect remains in feasibility and the desired timeline articulated by the Florida Health Care Administration, which sought to improve mitigation technology prior to the next hurricane season. Traditionally emergency management goes as follows: response, recovery, mitigation, preparation (Paul 2011). If the goal was to put mitigation in place before the next hurricane season so that facilities would be better prepared, Rule 59 A-4.1265 s initial timeline is necessary without extensions; however, since this timeline is not well aligned with the time needed to recover.

Mitigation technologies, such as generator upgrades or levees, are in high demand after a disaster but may require years of lobbying to plan, garner resources, and coordinate implementation (Paul 2011; Montz et al. 2017; Hutton et al. 2018). Reduced planning and implementation timelines for such undertakings may limit the benefits by reducing the potential for stakeholder input and comprehensive reform. Emergency power supply upgrades for Florida's nearly 700 nursing homes is a costly effort because, even if the individual facilities have the funds to make the improvements, they are reliant upon external contractors and government officials for supplies, installation, and inspection. There is a missed opportunity in Rule 59 A- 4.1265 because increased requirements to power additional equipment that would further reduce the vulnerability of nursing-home residents beyond heat stress, such as refrigerators for medication, are excluded. Additional research is needed to identify how to reconcile these competing priorities and propose policies that more comprehensively reduce vulnerability with achievable, urgent timelines.
This case study assesses organizational resilience in and proposes indicators of timely compliance in the elder-care industry. Two research questions are addressed: (i) what is the relationship between preexisting conditions of life-safety systems at facilities and date of implementation of emergency power regulation improvements and (ii) what is the role of interagency connections-such as emergency management, fire safety, health care administration, and electricity providers-in facilitating compliance with safety regulations. The existing capacity and processes to identify and correct safety deficiencies are analyzed. Findings establish a baseline for the conditions associated with timely compliance including the importance of agency connections to mitigate risk in nursing homes.

\section{Study area}

Research occurred in Collier and Polk Counties in Florida, for comparative purposes. Both counties were directly in the path of Hurricane Irma and have different electricity providers (Fig. 1). An urban location within each county was chosen for this research: the City of Lakeland in Polk County and the City of Naples in Collier County (Fig. 1).

\section{a. Demographics}

The potential demand for elder care in the immediate vicinity and within the broader city limits could influence the capacity to provide service following the declaration of a state of emergency. The population of Naples is 19537 while Lakeland's population is 106420 (U.S. Census Bureau 2012). Approximately $20 \%$ of Lakeland's population is 65 and older (Fig. 2). Approximately $50 \%$ of Naples residents are 65 or older (Fig. 3). An electrical outage that exceeds the amount of generator fuel available at a residence or facility could cause heat stress or prevent the use of life-sustaining technology and necessitate a search for the nearest facility to maintain that service. Hospitals in Lakeland and Naples are not intentionally collocated with the concentration of nursing homes or elderly residents, which may increase the incidence of preventable deaths if access is limited by storm-related debris or roadway damage (Figs. 2 and 3).

\section{b. Temperatures}

Lakeland and Naples experienced hot weather with temperatures in excess of $90^{\circ} \mathrm{F}\left(\sim 32^{\circ} \mathrm{C}\right)$ in the days following Hurricane Irma. Both locations also recorded dewpoints greater than $70^{\circ} \mathrm{F}$ $\left(\sim 21^{\circ} \mathrm{C}\right.$ ) (National Centers for Environmental Information 2017). Dewpoint directly effects human comfort - the higher the dewpoint, the muggier it will feel. Heat and high humidity reduce human thermoregulation, particularly for vulnerable populations such as the elderly.

At Lakeland Linder Regional Airport, maximum temperatures ranged from $86^{\circ}$ to $92^{\circ} \mathrm{F}\left(30^{\circ}-\sim 33^{\circ} \mathrm{C}\right)$ in the days following Hurricane Irma. Dewpoints exceeded $70^{\circ} \mathrm{F}$ daily. Similarly, Naples Municipal Airport recorded temperatures between $87^{\circ}$ and $91^{\circ} \mathrm{F}\left(\sim 31^{\circ}-\sim 33^{\circ} \mathrm{C}\right)$. While slightly lower than in Lakeland, Naples's $68^{\circ} \mathrm{F}\left(20^{\circ} \mathrm{C}\right)$ dewpoint coupled with the elevated maximum temperature, did not provide relief even during the overnight hours. Lows at Lakeland did not fall 


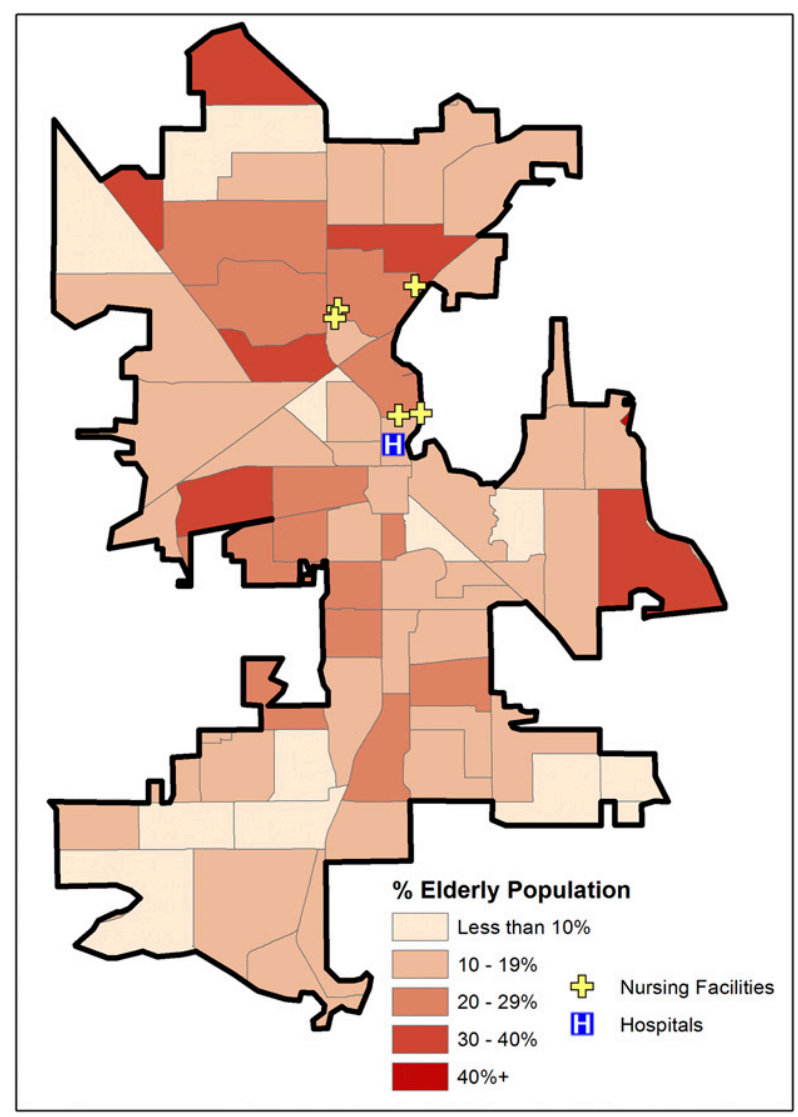

FIG. 2. Nursing-home locations in Lakeland (adapted from U.S. Census Bureau 2012).

below $75^{\circ} \mathrm{F}\left(\sim 24^{\circ} \mathrm{C}\right)$, and those at Naples remained $68^{\circ} \mathrm{F}$ and above in the time between Hurricane Irma and full power restoration (National Centers for Environmental Information 2017).

Temperatures in Naples exceeded the maximum $81^{\circ} \mathrm{F}$ allowed by Rule 59 A-4.1265 for 10 days and those in Lakeland for 8 days before power was fully restored. Nursing homes without power would have, consequently, exceeded the maximum temperature. Power was restored within 10 days in Lakeland and 12 days in Naples (Guinn 2017; Riley 2017).

A study of two other Florida counties after Hurricane Irma found approximately half of households used a generator and attributed it to an improved experience, but access varied based on race and past disaster experience (Chakalian et al. 2019). Chakalian et al. (2019) recommended "infrastructure like" generators to restore power to whole neighborhoods during prolonged power outages. Florida's nursing homes, by virtue of Rule 59 A-4.1265, offer insight into the challenges associated with implementing such an initiative.

Throughout Florida, Georgia, and North Carolina, 20 deaths were associated with a power outage compounding an existing medical condition, either from lack of air conditioning (AC) or failed medical equipment. Seventy percent (14 deaths) of these occurred at a skilled nursing facility in Florida without power for several days (Issa et al. 2018; Pierce and West 2017). Nursing homes and hospitals were prioritized by each county's

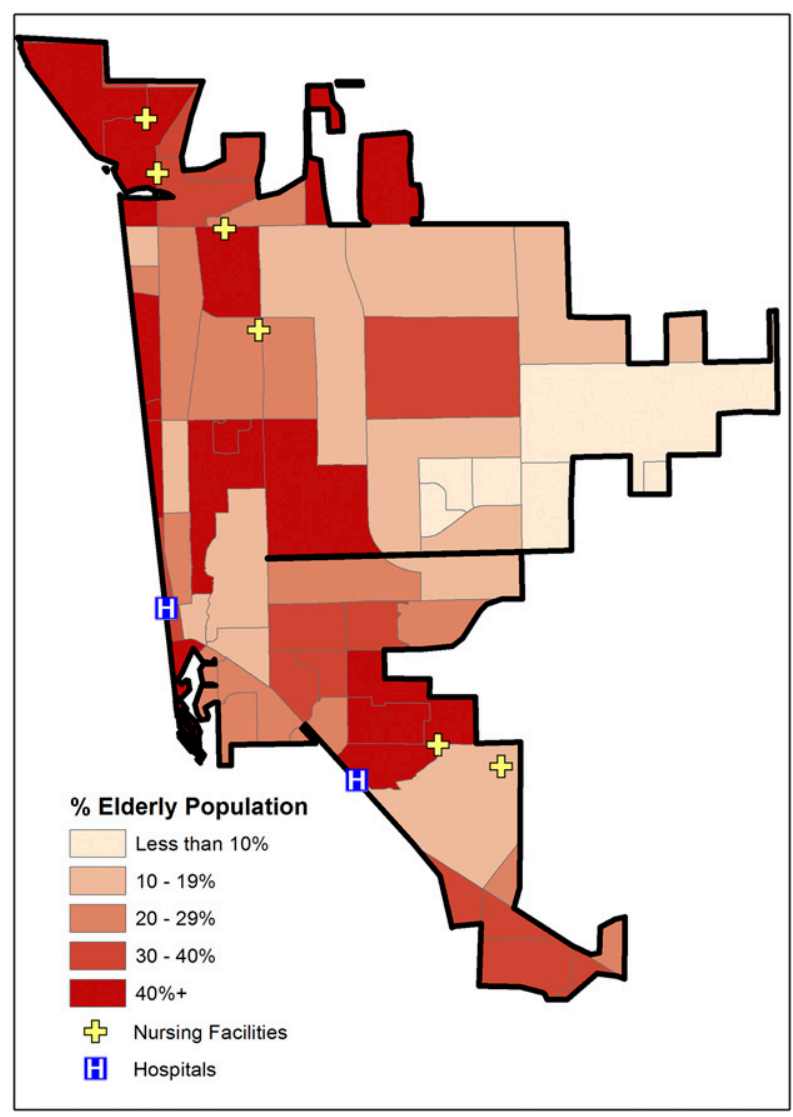

FIG. 3. Nursing-home locations in Naples.

emergency management agency and many had power restored sooner than other businesses and residents. Not all nursing homes in Naples and Lakeland lost power and those that did, even for a few hours, were able to activate existing generators.

\section{Method}

This research addresses gaps in the literature regarding the role of interagency connections in reducing timelines for compliance with hazard mitigation regulations in a postdisaster setting. It also analyzes the effects of preexisting technology deficiencies and utilization of external partners to remediate them upon implementation timelines for generator upgrades.

\section{a. Participant selection}

The facility and provider locator on the FloridaHealthFinder.gov website identified 11 nursing homes in Collier County and 24 in Polk County. A total of six nursing homes from each county were included in the study. Zip codes were the most detailed level of analysis available for comparing nursing homes. Those with more than one nursing home per zip code were selected from within the Naples area, including the following:

1) Harborchase of Naples and Solaris Senior Living North Naples in zip code 34109 ,

2) Bentley Care Center and Solaris Healthcare Imperial in zip code 34110 , and 


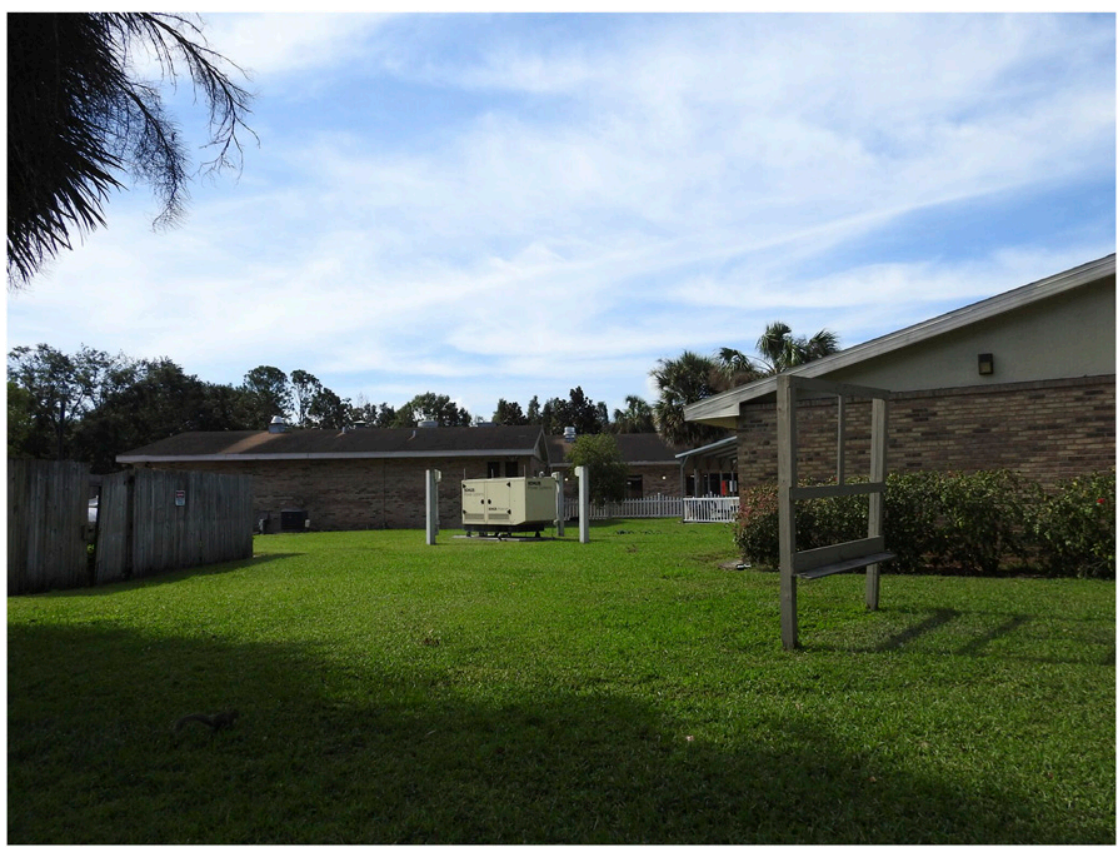

FIG. 4. Fixed generator-Lakeland.

3) The Arlington of Naples and Manorcare of Lely Palms in zip code 34113 .

Two zip codes within Lakeland had the highest concentration of nursing homes:

1) Consulate Health Care at Lake Parker, Lakeland Hills Center, and Lakeland Nursing and Rehabilitation in zip code 33805 and

2) Consulate Health Care of Lakeland, The Manor at Carpenters Way, and Wedgewood Healthcare Center in zip code 33809.

Although this is a small subset of nursing homes affected by the disaster, the range of health care and power infrastructure systems represented allowed for generalizations to be made about how emergency power supplies and interagency connections contribute to maintaining care.

\section{b. Data collection and analysis}

On-site observation was conducted on 8 and 9 October 2017-four weeks after Hurricane Irma passed through the two areas. This timeframe was selected to identify the facilities emergency power resources prior to the implementation of upgrades resulting from the governor's order. We visited each nursing home with publicly accessible grounds to document the presence of externally visible emergency power supplies, using a camera that encoded geographic coordinates to each photograph (Figs. 4 and 5 ). Gated facilities neither provided

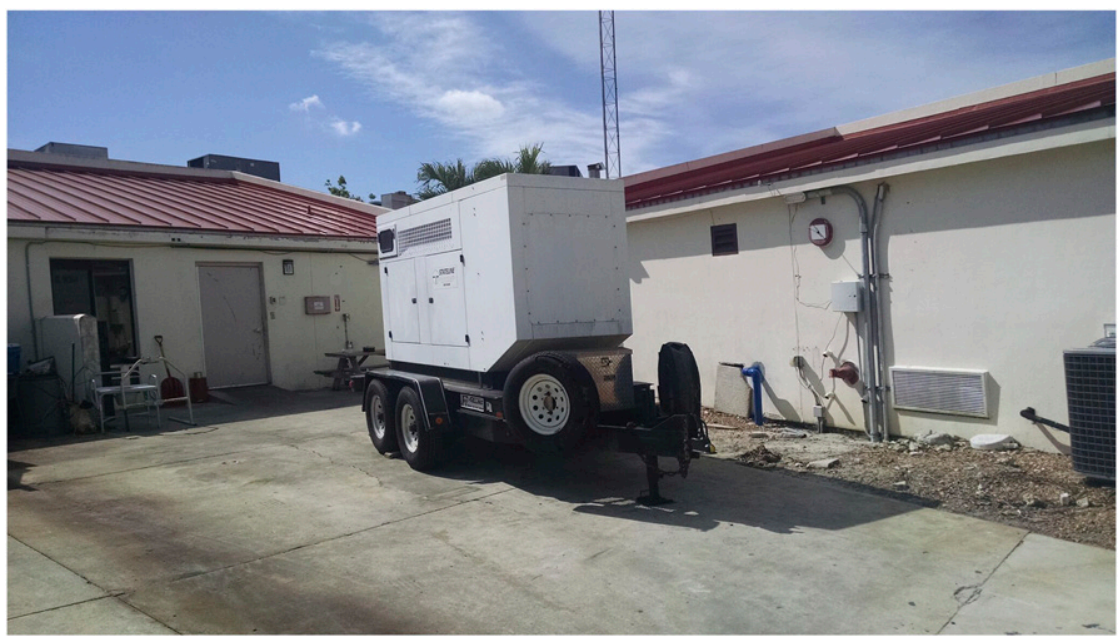

FIG. 5. Portable generator-Naples. 
TABLE 1. Polk County life-safety inspection results and corrective actions from 10 October 2016 through 10 October 2017 (source: adapted from Florida Agency for Health Care Administration Form 3020-001).

\begin{tabular}{|c|c|c|c|}
\hline Facility & Life-safety deficiencies & Corrective-action resources & Date \\
\hline Consulate Health Care of Lake Parker & None & Not applicable & 19 Jun 2017 \\
\hline Consulate Health Care of Lakeland & Exit door timing delay & $\begin{array}{l}\text { Internal signage; internal procedure } \\
\text { update }\end{array}$ & 28 Mar 2017 \\
\hline Lakeland Hills Center & None & Not applicable & 20 Jun 2017 \\
\hline Lakeland Nursing and Rehabilitation & Sprinkler maintenance & $\begin{array}{l}\text { External contractor repair; internal } \\
\text { procedure update }\end{array}$ & 10 May 2017 \\
\hline The Manor at Carpenters & None & Not applicable & 14 Feb 2017 \\
\hline Wedgewood Healthcare Center & $\begin{array}{l}\text { Fire alarm panel testing and } \\
\text { maintenance }\end{array}$ & $\begin{array}{l}\text { Internal maintenance; internal procedure } \\
\text { update }\end{array}$ & 5 Dec 2016 \\
\hline
\end{tabular}

physical access nor information via telephone or e-mail to those unaffiliated with government agencies or private electrical contractors during this transitional period. One Lakeland facility and three Naples facilities could not be photographed because gates prevented entry. A geographic information system was used to analyze the spatial distribution of hospital, emergency power resources, acute care facilities, and population demographics.

The progression of compliance with the governor's emergency action was determined from the consumerfriendly summaries of each nursing home's emergency power plan through January 2019 (Tables 1 and 2) (Florida Agency for Health Care Administration 2018b). Technological and interagency capacities to comply with fire safety requirements before the deadline were assessed from Florida Agency for Health Care Administration life-safety code inspection reports dated within a year of Hurricane Irma (Tables 3 and 4) (Florida Agency for Health Care Administration 2018b). These summaries and reports were quantitatively and qualitatively analyzed. Qualitative entries from both the reports and summaries were coded manually based on emergent themes: (i) technology or procedural violation, (ii) external or internal remediation, (iii) fixed or mobile generator, and (iv) partial or full facility emergency power supply. Relevant terms were paired with frequency counts to determine how often the various types of violations, remediation techniques, and improvement goals occurred.

\section{Results}

\section{a. Life-safety code inspections}

Life-safety code adherence in Florida nursing homes is assessed during annual unannounced inspections conducted by the fire marshal. Corrections in both cities required approximately one month to complete and be reinspected. Previous deficiencies indicate the timeliness with which nursing homes might comply with the new Emergency Action to maintain temperatures.

Three nursing homes in Lakeland and three in Naples did not have reported deficiencies in the year leading up to Hurricane Irma (Tables 1 and 2). Of the remaining three facilities in Polk County, deficiencies potentially associated with generator safety included delayed access to areas with door codes, missed fire alarm testing, and missed maintenance of fire alarms and sprinklers. External contractors were called to one facility to remediate deficiencies. Internal procedures were updated to reflect these remediation contracts and internal maintenance performed at two other facilities. At a facility shared by two health care providers one had deficiencies and the other did not.

Deficiencies reported in Naples nursing homes included inadequate signage for fire doors, missed tests of fire detectors and sprinklers, inaccessible hallways, and failure to conduct a systems risk assessment. External contractors were called to two facilities to remediate and consult on electrical risks. Internal procedures were updated to reflect these remediation

TABLE 2. Collier County life-safety inspection results and corrective actions from 10 October 2016 through 10 October 2017 (source: adapted from Florida Agency for Health Care Administration Form 3020-001).

\begin{tabular}{|c|c|c|c|}
\hline Facility & Life-safety deficiencies & Corrective-action resources & Inspection date \\
\hline Bentley Care Center & None & Not applicable & 31 Oct 2016 \\
\hline Harborchase of Naples & Fire door labeling; fire detector testing & Internal procedure update & 25 Sep 2017 \\
\hline Manorcare at Lely Palms & None & Not applicable & 13 Jun 2017 \\
\hline Solaris Healthcare Imperial & $\begin{array}{l}\text { Corridor accessibility; sprinkler testing; } \\
\text { building systems risk assessments }\end{array}$ & $\begin{array}{l}\text { Internal maintenance; internal procedure } \\
\text { updates; external contractor repair; } \\
\text { external contractor review }\end{array}$ & 8 May 2017 \\
\hline $\begin{array}{l}\text { Solaris Senior Living North } \\
\text { Naples }\end{array}$ & Fire detector testing & $\begin{array}{l}\text { Internal procedure update; external } \\
\text { contractor consultation }\end{array}$ & 7 Mar 2017 \\
\hline $\begin{array}{l}\text { The Arlington of } \\
\text { Naples, Inc. }\end{array}$ & None & Not applicable & 3 Jan 2017 \\
\hline
\end{tabular}


TABLE 3. Polk County nursing-home emergency power supply updates (generated by authors from consumer-friendly summaries of emergency power plans).

\begin{tabular}{|c|c|c|c|c|}
\hline Facility & Plan approved & Implementation & Emergency power supports & $\begin{array}{l}\text { Alternate power } \\
\text { source }\end{array}$ \\
\hline $\begin{array}{l}\text { Consulate Health Care at } \\
\text { Lake Parker }\end{array}$ & 27 Apr 2018 & 1 Jan 2019 & $\begin{array}{l}\mathrm{AC}, \text { life-safety systems, lights, and } \\
\text { refrigeration }\end{array}$ & Fixed generator \\
\hline $\begin{array}{l}\text { Consulate Health Care of } \\
\text { Lakeland }^{\mathrm{a}}\end{array}$ & 27 Apr 2018 & 1 Jan 2019 & $\begin{array}{l}\text { AC, life-safety systems, lights, and } \\
\text { refrigeration }\end{array}$ & Fixed generator \\
\hline Lakeland Hills Center & 24 Oct 2017 & 20 Oct 2017 & Not reported & Not reported \\
\hline $\begin{array}{l}\text { Lakeland Nursing and } \\
\text { Rehabilitation }^{\mathrm{a}}\end{array}$ & 12 Dec 2017 & 1 Jan 2019 & $\begin{array}{l}\mathrm{AC} \text {, heat, life-safety systems, lights, and } \\
\text { refrigeration }\end{array}$ & $\begin{array}{l}\text { Fixed and portable } \\
\text { generator }\end{array}$ \\
\hline The Manor at Carpenters & 24 Oct 2017 & 4 Oct 2017 & Entire facility & Fixed generator \\
\hline $\begin{array}{l}\text { Wedgewood Healthcare } \\
\text { Center }^{\mathrm{a}}\end{array}$ & 27 Apr 2018 & 1 Jan 2019 & $\begin{array}{l}\text { AC, life-safety systems, lights, and } \\
\text { refrigeration }\end{array}$ & Fixed generator \\
\hline
\end{tabular}

${ }^{\mathrm{a}}$ Deficiencies reported in life-safety inspection from within one year of Hurricane Irma.

contracts. The other nursing home in Naples had not corrected the deficiencies by the date of the study, but the time limitation to do so had not expired. Although successful maintenance of life safety was not consistent within counties or even the same facility, nursing homes across the state supplemented internal capacity and comprehension of life-safety requirements through relationships with external contractors and external inspection.

A lack of deficiencies related to generators from the year before Hurricane Irma indicates that generators were up to regulatory standards for storm induced power outages, however, the amount of space cooled per resident and duration of cooling was not as strictly regulated at that time. Collaborative oversight from fire marshals, county emergency management, and the Florida Agency for Health Care Administration guided the actions taken to ensure that technology was sufficient to prevent future heat-related deaths in nursing homes.

\section{b. Emergency power plans}

County emergency management approves comprehensive emergency plans for nursing homes and reports the date and a summary of the emergency power plan portion of the comprehensive plan to the Florida Agency for Health Care
Administration (2018a) (Tables 3 and 4). Revised emergency power plans were approved at two facilities in Lakeland and none in Naples by the original deadline set by the governor. By the end of 2017, one additional facility in Lakeland and one in Naples had approved plans. The remaining three facilities in Lakeland received approval in April 2018. Two additional plans were approved for Naples-based facilities by the end of May 2018. The other three were approved after the beginning of the next hurricane season, with the last one on 1 August 2018. Delays in plan approval might have occurred at the facility or emergency management level.

Building plans for expanded emergency power supplies are reviewed by the Florida Agency for Health Care Administration and inspections for compliance are completed by the local fire marshal. Compliance dates were reported in the consumer-friendly summaries (Tables 3 and 4). Three facilities, one in Naples and two in Lakeland, were compliant before the emergency action deadline. One Naples facility implemented its emergency power plan before its approval. The other facilities received extensions until 31 December 2018 or 1 January 2019. All the facilities with life-safety deficiencies from the past year had extensions for compliance (Tables 3 and 4). Similarly, all the facilities with extensions

TABLE 4. Collier County nursing-home emergency power supply updates (generated by authors from consumer-friendly summaries of emergency power plans).

\begin{tabular}{|c|c|c|c|c|}
\hline Facility & Plan approved & Implementation & Emergency power supports & Alternate power source \\
\hline Bentley Care Center & Not reported & 31 Dec 2018 & $\begin{array}{l}\text { Life-safety systems, lights, } \\
\text { elevator, and certain receptacles }\end{array}$ & $\begin{array}{l}\text { Fixed generator, fuel } \\
\text { storage transfer trailer, } \\
\text { and portable generator }\end{array}$ \\
\hline Harborchase of Naples ${ }^{a}$ & $\begin{array}{c}31 \text { May } 2018 \text { and } 29 \\
\text { Mar } 2019\end{array}$ & 1 Jan 2019 & Entire facility & Fixed generator \\
\hline Manorcare at Lely Palms & 5 Dec 2017 & 1 Jan 2019 & Not reported & Not reported \\
\hline $\begin{array}{l}\text { Solaris Healthcare } \\
\text { Imperial }^{\mathrm{a}}\end{array}$ & 1 Aug 2018 & 31 Dec 2018 & $\mathrm{AC}$ & Portable generator \\
\hline $\begin{array}{l}\text { Solaris Senior Living } \\
\text { North Naples }\end{array}$ & $23 \mathrm{Jul} 2018$ & 1 Jan 2019 & AC, lights, and refrigeration & Portable generator \\
\hline $\begin{array}{l}\text { The Arlington of } \\
\text { Naples, Inc. }\end{array}$ & 7 Jun 2018 & 8 Nov 2017 & $\begin{array}{c}\mathrm{AC}, \text { heat, life-safety systems, } \\
\text { lights, and refrigeration }\end{array}$ & Fixed generator \\
\hline
\end{tabular}

${ }^{a}$ Deficiencies reported in life-safety inspection from within one year of Hurricane Irma. 
until the last day of 2018 or first day of 2019 received additional extensions into 2019.

\section{c. Emergency power supplies}

The nursing homes without gated entry that were publicly accessible in both counties all had visible generators. Some were on wheels, while others were not mobile (Figs. 4 and 5). Fuel supplies and venting mechanisms were also evident at each facility.

Emergency power plans detailed the fuel source, generator capacity, and what it will support when upgraded (Tables 3 and 4). All the facilities in Lakeland will have fixed generators. Two facilities in Naples will have exclusively portable generators. One facility in each county will have a combination of fixed and portable generators. Each county had one facility where no data about the intended alternate power source was provided.

Although air conditioning or spot coolers will be supported by generators, only one facility in each county will be fully supported by emergency power. Heat will also be supported by emergency power supplies at one additional facility in each county. The Lakeland facilities generate power to support lifesafety systems, lights, and refrigeration. In Naples, life-safety systems, lights, and refrigeration will be supported at two, three, and two facilitates, respectively. One Naples facility, which uses spot coolers instead of air conditioning for emergency cooling, will power specific electrical outlets during an emergency, which may provide more options for what to run in addition to those. Supporting refrigeration, life-safety systems, lights, and power receptacles bolsters service provision in emergencies. For example, oxygen compressors require power to receptacles and some medications, such as those for diabetes, require refrigeration. Facilities that only meet the minimum requirement to support emergency power to air conditioning systems will be compliant but will not receive the full benefit of life-sustaining technologies.

\section{Conclusions}

The outcomes from these nursing homes show that basing legislation and implementation deadlines on public response does not necessarily result in timely execution or maximized safety benefits even when collective action is undertaken. The timely compliance with new emergency mitigation legislation is facilitated by compliance history including existing equipment and previous utilization of external partners. The occurrence of Hurricane Irma in these specific cities did not cause consistent implementation of new mitigation technology requirements prior to the next hurricane season.

For nursing homes to be more resilient, facility maintenance and relationships with technicians, county and state agencies should be prioritized. The facilities in this study have either become compliant or received extensions indicating that their agency connections have been sufficient to sustain perceived resilience throughout the implementation process. Ultimately, compliance with regulations or best practices regarding generator capacity will impact the ability for distributed power generation to provide resilience during emergencies.

Future mitigation policies should account for a range of facility resources including collective agency for the sector in setting implementation timelines. This study establishes a baseline for research on the role of agency and experience in precautionary mitigation at nursing homes. Similar approaches may be used for other hazardous events (e.g., Abi-Samra and Malcolm 2011).

Hurricane Irma reiterated the need for continuous improvement and monitoring of emergency preparedness for nursing homes in the state of Florida. The state may benefit from continued longitudinal analysis of compliance with and expansion beyond emergency power generation requirements. Perceived increases in preparedness by nursing-home administration, government partners, mitigation technicians, as well as, nursing-home residents, their families, and Florida voters should also be assessed through interviews, surveys, and focus groups to determine the effectiveness of Rule 59 A-4.1265 for the sector. Further, emergency simulations should be conducted with nursing-home administration and staff, as well as external contractors and officials (Whytlaw 2018). Emergency exercises allow for detailed network analysis and testing of updated comprehensive emergency plans including generator capacity increases, transfer agreements with hospitals and preferred provider agreements with electrical technicians, which are critical to preventing adverse health outcomes from power failure. Because these documents are exempt public records, which are not accessible during ongoing litigation or increased security concerns, both agency connections and public opinion may benefit from such emergency exercises.

Standards for emergency power supplies at nursing homes should consider the area's temperatures and power failure risk, as well as industry-specific resources. The surrounding population and facility mitigation options remain at risk until infrastructure for emergency power supplies at nursing homes is improved to withstand prolonged outages. Regional and comparative studies at elder-care facilities should be conducted to establish a framework for managing interagency connections to promote rapid policy development and implementation to mitigation of heat exposure.

Acknowledgments. This research was funded in part by a grant from the University of Colorado Natural Hazards Center through its Quick Response Grant Program, which is funded by National Science Foundation Grant CMMI 1333610.

Data availability statement. Data were derived from public records. Authors will make geographic coordinates of visible generators available upon reasonable request.

\section{REFERENCES}

Abi Ghanem, D., S. Mander, and C. Gough, 2016: "I think we need to get a better generator": Household resilience to disruption to power supply during storm events. Energy Policy, 92, 171180, https://doi.org/10.1016/j.enpol.2016.02.003.

Abi-Samra, N. C., and W. P. Malcolm, 2011: Extreme weather effects on power systems. 2011 IEEE Power and Energy Society General Meeting, Detroit, MI, IEEE, 1-5, https://doi.org/ 10.1109/PES.2011.6039594.

Aldrich, N., and W. F. Benson, 2008: Peer reviewed: Disaster preparedness and the chronic disease needs of vulnerable older adults. Prev. Chronic Dis., 5, A27. 
Anderson, G., and M. Bell, 2012: Lights out: Impact of the August 2003 power outage on mortality in New York, NY. Epidemiology, 23, 189-193, https://doi.org/10.1097/EDE.0b013e318245c61c.

Åström, D. O., F. Bertil, and R. Joacim, 2011: Heat wave impact on morbidity and mortality in the elderly population: A review of recent studies. Maturitas, 69, 99-105, https://doi.org/10.1016/ j.maturitas.2011.03.008.

Beatty, M. E., S. Phelps, C. Rohner, and I. Weisfuse, 2006: Blackout of 2003: Public health effects and emergency response. Public Health Rep., 121, 36-44, https://doi.org/10.1177/ 003335490612100109.

Brown, L. M., K. Hyer, and L. Polivka-West, 2007: A comparative study of laws, rules, codes and other influences on nursing homes' disaster preparedness in the Gulf Coast states. Behav. Sci. Law, 25, 655-675, https://doi.org/10.1002/bsl.785.

Byrd, H., and S. Matthewman, 2014: Exergy and the city: The technology and sociology of power (failure). J. Urban Technol., 21, 85-102, https://doi.org/10.1080/10630732.2014.940706.

Chakalian, P. M., L. C. Kurtz, and D. M. Hondula, 2019: After the lights go out: Household resilience to electrical grid failure following Hurricane Irma. Nat. Hazards Rev., 20, 05019001, https://doi.org/10.1061/(ASCE)NH.1527-6996. 0000335 .

CMS, 2016: Emergency preparedness requirements for Medicare and Medicaid participating providers and suppliers final rule. Department of Health and Human Services, accessed 19 June 2020, https://www.cms.gov/Medicare/Provider-Enrollment-andCertification/SurveyCertEmergPrep/Emergency-Prep-Rule.

Eisenman, D. P., and Coauthors, 2016: Heat death associations with the built environment, social vulnerability and their interactions with rising temperature. Health Place, 41, 89-99, https://doi.org/10.1016/j.healthplace.2016.08.007.

Florida Agency for Health Care Administration, 2017: AHCA and DOEA announce new permanent generator rules have been filed. Accessed 30 August 2018, https://ahca.myflorida. com/Executive/Communications/Press_Releases/pdf/AHCA andDOEAAnnouncetheNewPermanentGeneratorRulesHave BeenFiled.pdf.

__ 2018a: Important tips to ensure safety when using generators. Accessed 30 August 2018, http://ahca.myflorida.com/MCHQ/ Emergency_Activities/docs/GeneratorSafetyBrochure.pdf.

_ 2018b: Facility/provider locator. Accessed 30 August 2018, https://www.floridahealthfinder.gov/facilitylocator/facloc.aspx.

Florida Division of Emergency Management, 2017a: Gov. Scott: I am aggressively fighting to keep vulnerable Floridians safe during emergencies. Accessed 24 September 2020, https:// www.floridadisaster.org/news-media/news/gov.-scott-i-amaggressively-fighting-to-keep-vulnerable-floridians-safe-duringemergencies/.

_- 2017b: Outage reports. Accessed 15 October 2017, https:// www.floridadisaster.org/news-media/news/gov.-scott-morethan-65-percent-of-power-outages-restored-statewide/.

Gronlund, C. J., A. Zanobetti, G. A. Wellenius, J. D. Schwartz, and M. S. O'Neill, 2016: Vulnerability to renal, heat and respiratory hospitalizations during extreme heat among U.S. elderly. Climatic Change, 136, 631-645, https://doi.org/10.1007/s10584016-1638-9.

Guinn, C., 2017: Power restored in Polk after Irma? It's all in the definition. Ledger, accessed 20 September 2017, https:// www.theledger.com/news/20170920/power-restored-in-polkafter-irma-its-all-in-definition.

Hajat, S., M. O'Connor, and T. Kosatsky, 2010: Health effects of hot weather: From awareness of risk factors to effective health protection. Lancet, 375, 856-863, https://doi.org/ 10.1016/S0140-6736(09)61711-6.

Helsloot, I., and R. Beerens, 2009: Citizens' response to a large electrical power outage in the Netherlands in 2007. J. Contingencies Crisis Manage., 17, 64-68, https://doi.org/10.1111/j.14685973.2009.00561.x.

Hiete, M., M. Merz, and F. Schultmann, 2011: Scenario-based impact analysis of a power outage on healthcare facilities in Germany. Int. J. Disaster Resilience Built Environ., 2, 222-244, https://doi.org/10.1108/17595901111167105.

Hutton, N., 2018: Sustaining resilience: Modeling nonprofit collaboration in recovery. Prof. Geogr., 70, 655-665, https:// doi.org/10.1080/00330124.2018.1443479.

_- 2019: Institutionalizing nonprofit influences on post-disaster vulnerability reduction. Emerging Voices in Natural Hazards Research, F. Rivera, Ed., Butterworth-Heineman, 251-284.

- G. Tobin, and L. Whiteford, 2016: Modeling non-profit resilience in long-term recovery in Christchurch, New Zealand. Prof. Geogr., 68, 603-612, https://doi.org/10.1080/00330124.2015.1135402.

_, _ - and B. Montz, 2018: The levee effect revisited: Processes and policies enabling development in Yuba County, California. J. Flood Risk Manage., 12, e12469, https://doi.org/ 10.1111/JFR3.12469.

Hyer, K., 2013: For long-term care, readiness gaps abound. Health Prog., 94, 42-49.

—, L. M. Brown, A. Berman, and L. Polivka-West, 2006: Establishing and refining hurricane response systems for longterm care facilities. Health Aff., 25, w407-w411, https:// doi.org/10.1377/hlthaff.25.w407.

— , L. Polivka-West, and L. Brown, 2007: Nursing homes and assisted living facilities: Planning and decision making for sheltering in place or evacuation. Generations, 31, 29-35.

Issa, A., and Coauthors, 2018: Deaths related to Hurricane Irma-Florida, Georgia, and North Carolina, September 4October 10, 2017. Morb. Mortal. Wkly. Rep., 67, 829-832, https://doi.org/10.15585/mmwr.mm6730a5.

Kile, J. C., and Coauthors, 2005: Impact of 2003 power outages on public health and emergency response. Prehosp. Disaster Med., 20, 93-97, https://doi.org/10.1017/S1049023X00002259.

Klinger, C., O. Landeg, and V. Murray, 2014: Power outages, extreme events and health: A systematic review of the literature from 2011-2012. PLOS Curr. Disasters, 6, https://doi.org/ 10.1371/currents.dis.04eb1dc5e73dd1377e05a10e9edde673.

Kovats, R. S., and S. Hajat, 2008: Heat stress and public health: A critical review. Annu. Rev. Public Health, 29, 41-55, https:// doi.org/10.1146/annurev.publhealth.29.020907.090843.

Montz, B. E., G. A. Tobin, and R. R. Hagelman III, 2017: Natural Hazards: Explanation and Integration. Guilford Press, 444 pp.

Myers, N., and A. Bearss, 2018: Mandating public health emergency preparedness: Analysis of the CMS rule. Risks Hazards Crisis Public Policy, 9, 278-302, https://doi.org/10.1002/rhc3.12138.

National Centers for Environmental Information, 2017: Climate data online. NOAA, accessed 5 December 2017, https:// www.ncdc.noaa.gov/cdo-web/.

NHC, 2017: Hurricane Irma advisory archive. NOAA, accessed 10 December 2017, http://www.nhc.noaa.gov/archive/2017/ IRMA.shtml.

Oleske, D. M., 2001: An epidemiological model of the delivery of health care services. Epidemiology and the Delivery of Health Care Services: Methods and Applications, Springer, 3-28.

Palm, J., 2009: Emergency management in the Swedish electricity grid from a household perspective. J. Contingencies Crisis Manage., 17, 55-63, https://doi.org/10.1111/j.1468-5973.2009.00557.x. 
Panteli, M., and P. Mancarella, 2015: Influence of extreme weather and climate change on the resilience of power systems: Impacts and possible mitigation strategies. Electr. Power Syst. Res., 127, 259-270, https://doi.org/10.1016/j.epsr.2015.06.012.

Paul, B. K., 2011: Environmental Hazards and Disasters: Contexts, Perspectives and Management. John Wiley and Sons, 322 pp.

Pescaroli, G., and D. Alexander, 2016: Critical infrastructure, panarchies and the vulnerability paths of cascading disasters. Nat. Hazards, 82, 175-192, https://doi.org/10.1007/s11069-0162186-3.

Pierce, J. R., Jr., and T. A. West, 2017: Helping nursing homes shelter-in-place. J. Emerg. Manage., 15, 341-342, https:// doi.org/10.5055/jem.2017.0342.

Qureshi, K., R. R. M. Gershon, M. F. Sherman, T. Straub, E. Gebbie, M. McCollum, M. J. Erwin, and S. S. Morse, 2005: Health care workers' ability and willingness to report to duty during catastrophic disasters. J. Urban Health, 82, 378-388, https://doi.org/10.1093/jurban/jti086.

Riley, P., 2017: Hurricane Irma: FPL says some on Gulf Coast may lack power until September 22. Naples Daily News, accessed 12 September 2017, https://www.naplesnews.com/story/weather/ hurricanes/2017/09/12/hurricane-irma-fpl-has-20-000-employeesworking-restore-power-west-coast-take-longer/657714001/.

Root, E. D., J. B. Amoozegar, and S. L. Bernard, 2007: Nursing homes in public health emergencies: Special needs and potential roles. Agency for Healthcare Research and Quality, U.S. Department of Health and Human Services, accessed 19 June 2019, https://www.hsdl.org/?view\&did=479429.
Senkbeil, J., J. Collins, and J. Reed, 2019: Evacuee perception of geophysical hazards for Hurricane Irma. Wea. Climate Soc., 11, 217-227, https://doi.org/10.1175/WCAS-D-18-0019.1.

— , and Coauthors, 2020: Perceptions of hurricane-track forecasts in the United States. Wea. Climate Soc., 12, 15-29, https:// doi.org/10.1175/WCAS-D-19-0031.1.

Sexton, C., 2018: Nursing homes want more time to meet generator requirements. Sun Sentinel, accessed 18 November 2018, https://www.sun-sentinel.com/local/broward/fl-ne-nsf-nursinghome-generators-20181116-story.html.

Sheridan, S. C., and M. J. Allen, 2018: Temporal trends in human vulnerability to excessive heat. Environ. Res. Lett., 13, 043001, https://doi.org/10.1088/1748-9326/aab214.

Smith, S. M., M. J. Tremethick, P. Johnson, and J. Gorski, 2009: Disaster planning and response: Considering the needs of the frail elderly. Int. J. Emerg. Manage., 6, 1-13, https://doi.org/ 10.1504/IJEM.2009.025170.

U.S. Census Bureau, 2012: TIGER/Line census tracts 2010. Accessed 15 December 2017, https://www.census.gov/geo/ maps-data/data/tiger-line.html.

Weichselgartner, J., and I. Kelman, 2015: Geographies of resilience: Challenges and opportunities of a descriptive concept. Prog. Hum. Geogr., 39, 249-267, https://doi.org/10.1177/ 0309132513518834.

Whytlaw, J. L., 2018: Great expectations: Environmental hazard incident prevention at New Jersey facilities that serve seniors. Ph.D. dissertation, Rutgers, The State University of New Jersey, 227 pp., https://doi.org/doi:10.7282/T3ZK5M4S. 